Original Article

\title{
DRUG UTILIZATION BASED ADRS DETECTION OF ANTIBIOTICS PRESCRIBED FOR LRTI IN TERTIARY CARE TEACHING HOSPITAL, NEW DELHI
}

\author{
MD SHAMIM1', MOHAMMAD DAUD ALI ${ }^{2 *}$, MD SARFARAZ ALAM, MD SAJID ALI, SARFARAZ AHMAD, MD \\ SALAHUDDIN ANSARI
}

${ }^{1}$ College of Pharmacy, Teerthanker Mahaveer University, Muradabad U. P India, ${ }^{2}$ Department of Pharmacy, Mohammed Almana College of Health Sciences, Abdulrazaq Bin Hammam Street, As Safa, Dammam 34222 KSA, 3,4,5Department of Pharmaceutics, College of Pharmacy, Jazan University, Jazan, KSA, ${ }^{6}$ Department of Pharmacy Practice, College of Pharmacy Aldawadmi, Shaqra University, Saudi Arabia Email: dali.niper@gmail.com

Received: 28 Oct 2017 Revised and Accepted: 24 Feb 2018

\section{ABSTRACT}

Objective: Aim of to present study was to assess drug utilization pattern of antibiotics use in Lower respiratory tract infection and their adverse drug reaction assessment.

Methods: The present study was an observational and prospective study. 110 patients fulfill the inclusion criteria were included in study. Physician prescription records, patient's medication profile types of antibiotics prescribed were recorded and analyzed.

Results: Out of 110 LRTI patients, $74(67.27 \%)$ patients were male and 36(32.72\%) patients were female. 72 patients were suffered from bronchitis while 38 patients were suffering from pneumonia. 30 patients were in the age range of 56-65 y, followed by 21 patients who were in the age range of 66-75 y. It has been observed that among all the prescribed antibiotic agent's frequency of $\beta$-lactam 199(45.53\%), quinolones115 (26.27\%), macrolides 53(12.12\%) chloramphenicol44 (10.06\%) sulphonamide $17(3.89 \%)$ and aminoglycosides $9(2.05 \%)$ were prescribed to all the patients. Average 3.97 antibiotic agents were prescribed to all the patients. Majority of drugs were given by oral route (68.19\%) and Prescriptions are mainly ordered in brand names. The most frequent co-morbid condition was found to be diabetes mellitus (25.45\%) followed by hypertension $(16.36 \%)$ and coronary artery disease (11.81\%).45.45\%. Only 23 ADRs were detected in 110 patients. The most common culprit was an amoxicillin with clavulanic acid.

Conclusion: The present study provides an overall pattern of antibiotic usage in different patients. The area of concern in the present study is polypharmacy and use of antibiotics in LRTI without following any guideline. ADRs monitoring is also required to prevent noxious effects of drugs by the use of antibiotics.

Keywords: Drug utilization Review, Adverse drug reaction (ADR), Lower respiratory tract infection (LRTI), Inpatient, Outpatient

(C) 2018 The Authors. Published by Innovare Academic Sciences Pvt Ltd. This is an open access article under the CC BY license (http://creativecommons.org/licenses/by/4.0/) DOI: http://dx.doi.org/10.22159/ijpps.2018v10i4.23368

\section{INTRODUCTION}

Lower respiratory tract infections (LRTIs) are the most common types of respiratory tract infections and it's a common cause of morbidity and mortality. Although viruses are a frequent cause of LRTIs [1], these may lead to secondary bacterial infections such as bronchitis and pneumonia [2]. These bacteria namely; Streptococcus pneumonia, Haemophilus influenza, Klebsiella pneumonia Mycoplasma pneumonia Staphylococcus aureus and Chlamydia pneumonia are mainly responsible for infections [3]. Among these, the infections caused by $S$. pneumoniae are considered to be more responsible for morbidity and mortality among the patients [4]. Diseases of the LRTI affect the functioning of adults as well as children, usually with significant impairment of the daily life of affected patients [5]. It has been envisaged that with an increase in global population, infections remain the most important causes of disease, with LRTIs causing bronchitis and pneumonia learning disability, especially in adults.

These were the fourth major cause of mortality and responsible for 4.0 million deaths or $6.9 \%$ of a global number of deaths in 2002 [6].

The majority of the antibiotics were prescribed for LRTI with a presumed viral etiology such as pneumonia and acute bronchitis. The results from observation were showing that antibiotic prescriptions are made in approximately $40 \%$ of all consultations for pneumonia and in $80 \%$ of those for acute bronchitis. Antibiotics were prescribed in more than $90 \%$ of cases of pneumonia irrespective of the age of the patients. The condition differed for acute bronchitis infections as the number of consultations has remained unchanged over the last decade while antibiotic prescriptions have strongly increased, reaching $80 \%$ of the consultations [7]. The inconsistency of antibiotic prescription is attributable to real differences, from country to country or even region to region, of the infecting organisms and antimicrobial susceptibility, but other factors may also involve including physician preference, local policy, costs, lack of local proper guidelines [8].

Currently, all over the world increase in resistant bacteria and simultaneously the downward tendency in the development of new antibiotics have serious health and economic issues. Throughout world an extensive overuse of antibiotics such as incorrect medical indications as well as misuse by using the wrong agent, route of administration, dose and treatment duration. Development of resistance is a natural biological consequence of antibiotic use. "Poor patient compliance with dosage regimens and the use of substandard antibiotics lead to suboptimal concentrations that fail to control the infections and it may promote the growth of resistant bacterial population thus, underuse, irrational use may play a vital role in driving resistance as overuse". At present, the ideal antibiotic does not exist and the overuse of broad-spectrum agents in respiratory infections motivates resistance development in pathogenic bacteria as well as in the normal bacterial population to the patients [9]. The resistance problem is most prominent in Asian continent. Particular, the rates of resistant for pneumococci in Asian countries have been alarming. In India, almost $100 \%$ of the healthy population carries bacteria that are resistant to antibiotics [10].

Even after the use of antibiotics for many years, there is little knowledge about how these drugs to be used optimally for the treatment. A core unanswered question is that how antibiotics 
should be administered to minimize resistance development without compromising safety and efficacy. There is a need to study on both antibiotic uses and causes of use from all regions of the world. In too many countries there is inadequate surveillance of prescribing the drug, quality of the drug, and the resistance problem. As per European surveillance of antibiotics consumption (ESAC), significant improvements in the surveillance of antibiotics use in Europe have been succeeded. However, a global approach is needed where comparable data are generated [9].

LRTIs infections place a considerable burden on the health care system and are generally more serious than upper respiratory infections. Since 2005 there has been a slight fall in the total number of loss of life from LRTI. However, in 2007, there was still the prominent cause of deaths among all infectious diseases accounting for 3.9 million deaths worldwide and $6.9 \%$ of total deaths that year [11]. Therefore, these evidence reflect drug utilization are required, as they evaluate the suitability of drug therapy. Drug use evaluation is an ongoing, authorized and systemic quality improvement process, which is designed to review the drugs which are prescribed to the patients, provide a right feedback to the clinician/ another relevant healthcare professional, develop criteria and standards; which describe optimal use of drug, promote suitable drug use through education and by counseling to the patients. Prospective drug utilization studies can directly impact the patient treatment and their outcome.

\section{MATERIALS AND METHODS}

It was prospective drug utilization evaluation and ADR monitoring of antibiotics in lower respiratory tract infections in Medicine Department, Majeedia Hospital, New Delhi-110062.

\section{Ethical approval}

The clinical protocol entitled "Drug utilization pattern and adverse drug reactions (ADRs) monitoring of antibiotics use in lower respiratory tract infections" was reviewed and approved by Institutional Review Board (IRB), Jamia Hamdard, New Delhi110062 ethical approval number is 24/01/011-02/11.

\section{Study site}

Study was carried out in the IPD and OPD of Medicine department of Majeedia Hospital; a 150 bedded teaching hospital situated in the premises of Jamia Hamdard New Delhi-110062.

\section{Study population}

Study was conducted on all eligible 110 patients at Majeedia Hospital, who had willingly participated; subjects were enrolled on the basis of inclusion and exclusion criteria.

\section{Selection of patients}

\section{Inclusion criteria}

a. All patients using antibiotics visiting OPD and IPD of Medicine Department in Majeedia Hospital New Delhi 110062

b. All the patients were included irrespective of age and sex.

c. Pregnant and lactating patients were also included.

\section{Exclusion criteria}

a. Mentally retarded and unconscious patients.

b. Patients who are not treated with antibiotics.

c. Patients unable to comply.

d. Drug addicts.

\section{Sources of data}

1) Physicians prescribing records.

2) Patient's medication profile.

\section{Evaluation of parameters}

The following parameters were evaluated:

1. Types of antibiotics prescribed

2. Average number of antibiotics per prescription

3. Average age range of patients utilizing antibiotics

4. Comparison of antibiotics prescribed in monotherapy vs. fixeddose combination therapy

5. Comparison of antibiotics prescribing by generic vs. brand name

6. Compliance or adherence (using Weekly Diary Cards) a criterion for non-compliance is $<80 \%$ of recommended intake of prescribed drugs.

7. Mode of administration of drugs

8. Concomitant diseased conditions

9. Most commonly used agents of a particular class

10. Monitoring/recording of adverse drug reactions (ADRs) due to antibiotics.

\section{Informed consent form}

Written consent was obtained from the subjects participated in the study in the informed consent form, which is attached as Annexure I.

\section{Materials used}

Medication Utilization and ADR Monitoring (MUADRM) form, attached as annexure I and follow up form, attached as annexure II.

\section{Data collection}

The following data was collected based on the questionnaire.

1. Patient profile (age, sex, weight, patient address, marital status).

2. Drugs prescribed (generic/brand name)

3. Drugs dose and frequency

Written consent was obtained and interviews were conducted by using structured questionnaire (open question method).

Weekly diary cards for daily drug intake to monitor adherence to prescribed dosage regimen was used. A criterion for non-compliance is $<80 \%$ of recommended intake of the prescribed drug. Weekly diary card is attached as annexure III.

\section{RESULTS}

\section{Distribution characteristics among study population}

A total of around 2100 patients (suffering from various diseases) visited the LRTI outpatient and inpatient in Medicine Department, Majeedia Hospital over a period of 4 mo. 110 patients suffering from bronchitis and pneumonia infections were selected for the present study.

\section{Demographic distribution amongst LRTI patients}

Among the 110 LRTI patients, 74 patients were male and 36 patients were female fig. 1 . It was observed that 30 patients were in the age range of $56-65 \mathrm{y}$, followed by 21 patients who were in the age range of $66-75$ y fig. 2

\section{Smokers vs. non-smokers and amongst LRTI patients}

32 patients were current smokers; amongst them 21 males and 11 females. Among 59 patients were ex-smokers including 40 males and 19 females. 19 were non-smokers comprising 13 males and 6 females table 1.

Alcoholics vs. non-alcoholics and tobacco chewers vs. Nontobacco characteristics

It was observed that 50 males and 16 females were alcoholics. Remaining 44 were Non-alcoholics including 24 males and 20 females table 2 . We found that 68 patients were tobacco chewers, 60 amongst them were males and 8 were females table 2. 


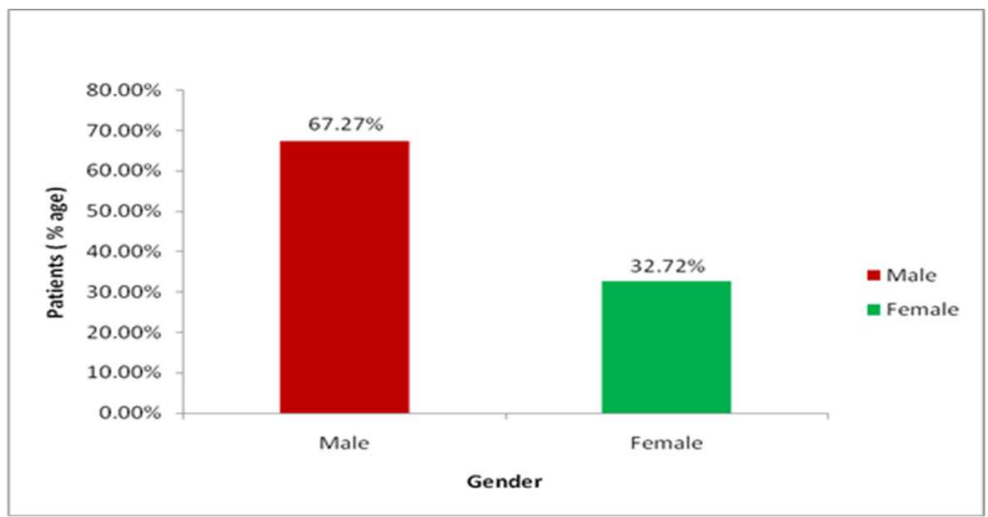

Fig. 1: Gender distribution amongst LRTI patients

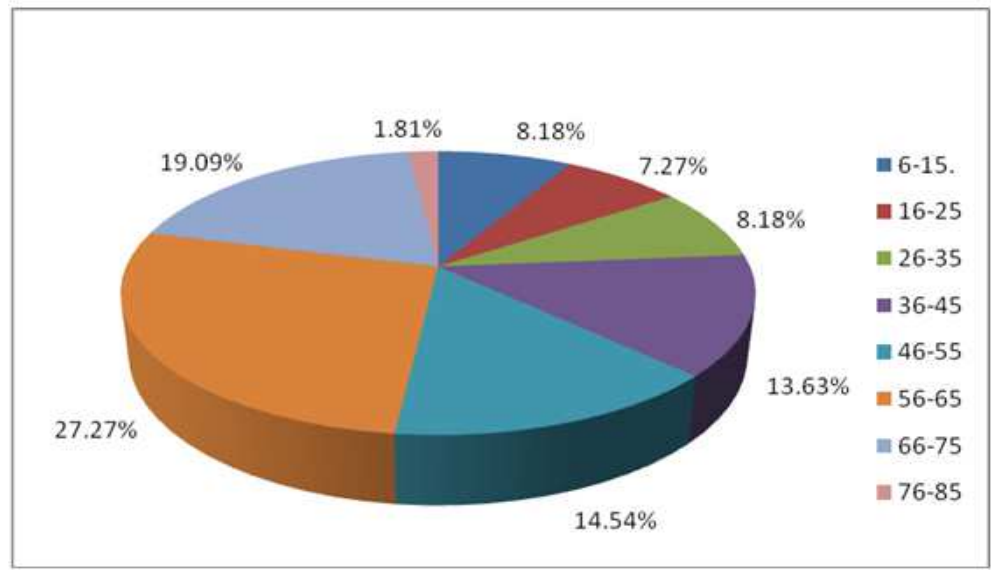

Fig. 2: Age distribution amongst LRTI patients

Table 1: Smokers vs. non-smokers amongst LRTI patients among LRTI patients

\begin{tabular}{llll}
\hline Smoking status & No. of males & No. of females \\
\hline Current smokers & 21 & 11 & \\
Ex-smokers & 40 & 19 & 32 \\
Non smokers & 13 & 6 & 59 \\
Total & 74 & 36 & 19 \\
\hline
\end{tabular}

Table 2:Alcoholics Vs non-alcoholics and tobacco chewers Vs. non-tobacco chewers amongst LRTI patients

\begin{tabular}{lll}
\hline Gender & Alcoholic & Non-alcoholic \\
\hline Male & $50(45.45 \%)$ & $24(21.81 \%)$ \\
Female & $16(14.54 \%)$ & $20(18.18 \%)$ \\
Total & $66(59.99 \%)$ & $44(39.99 \%)$ \\
Gender & Tobacco chewers & Non-tobacco chewers \\
Male & $60(54.54 \%)$ & $14(12.72 \%)$ \\
Female & $8(7.27 \%)$ & $28(25.45 \%)$ \\
Total & $68(61.81 \%)$ & $42(40.90 \%)$ \\
\hline
\end{tabular}

\section{Work status}

It was noted that 12 patients were employed, 8 were students, 11 were housewives, 18 were a businessman, 30 were retired, and 15 were unemployed and remaining 16 were others fig. 3.

\section{Types of infections}

Out of 110 patients, 72 patients suffered from bronchitis and 38 patients were suffering from pneumonia table 3 .

\section{Type of antibiotics prescribed}

During the study, it was observed that the most frequently prescribed antibiotic were $\beta$-lactam (199) followed by quinolones (115) macrolides (53) chloramphenicol (44) sulphonamide (17) cephalosporin (95) and aminoglycosides (9). Details of antibacterial utilization are given table 4 .

\section{Most commonly used the agent of a particular class}

The most commonly used agent of the most commonly used class i.e., $\beta$-lactam was Penicillins-amoxicillin with clavulanic acid (91) and Cephalosporins-cefuroxime followed by quinolones-gemifloxacin (61) chloramphenicol (44) macrolides-azithromycin (40) Sulphonamide Co-trimoxazole (17) and aminoglycoside-neomycin with polymyxin B (6) table 5 .

\section{Type of antibiotics therapy}

Prescription of patients showed that total of 60 patients received antibiotic monotherapy; whereas 18 patients were on multiple 
drug therapy. Among those who were treated with drug combinations, 14 patients received two drugs; 8 patients received three drugs and 10 patients received four drug regimens table 6 .

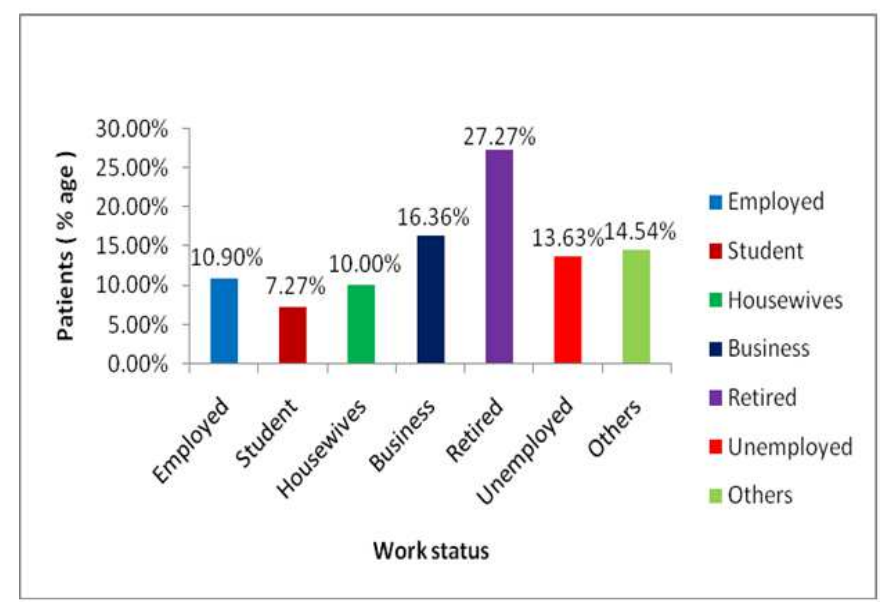

Fig. 3: Work status amongst LRTI patients

Table 3: Type of infection

\begin{tabular}{lll}
\hline Infection & Type & No. of patients \\
\hline Bronchitis & Acute Bronchitis & 39 \\
& Chronic Bronchitis & 33 \\
& Total & 72 \\
& Community-Acquired pneumonia & 23 \\
Pneumonia & Hospital Acquired pneumonia & 15 \\
& Total & 38 \\
Grand total & & 110 \\
\hline
\end{tabular}

Table 4: Type of antibiotics prescribed

\begin{tabular}{|c|c|c|c|}
\hline Class & Antibiotics agents & No. of agents prescribed & \% consumption \\
\hline \multirow[t]{7}{*}{ Quinolones } & Ciprofloxacin & 3 & 0.68 \\
\hline & Norfloxacin & 2 & 0.45 \\
\hline & Ofloxacin & 27 & 6.17 \\
\hline & Levofloxacin & 4 & 0.91 \\
\hline & Gatifloxacin & 18 & 4.11 \\
\hline & Gemifloxacin & 61 & 13.95 \\
\hline & Total & 115 & 26.27 \\
\hline \multirow[t]{15}{*}{ Beta-lactams } & Penicillins & & \\
\hline & Amoxicillin & 10 & 2.28 \\
\hline & Amoxicillin+Clavulanic acid & 91 & 20.82 \\
\hline & Amoxicillin+Cloxacillin & 3 & 0.68 \\
\hline & Cephalosporins & & \\
\hline & Cefadroxil & 5 & 1.14 \\
\hline & Cefuroxime & 23 & 5.26 \\
\hline & Cefaclor & 5 & 1.14 \\
\hline & Cefdinir & 8 & 1.83 \\
\hline & Cefpodoximeproxetil & 13 & 2.97 \\
\hline & Cefixime & 6 & 1.37 \\
\hline & Cefixime+Cloxacillin & 18 & 4.11 \\
\hline & Cefpirome & 15 & 3.43 \\
\hline & Cefditroenpivoxil & 2 & 0.45 \\
\hline & Total & 199 & 45.53 \\
\hline \multirow[t]{2}{*}{ Sulphonamide } & Co-trimoxazole & 17 & 3.89 \\
\hline & Total & 17 & 3.89 \\
\hline Chloramphenicol & & 44 & 10.06 \\
\hline \multirow[t]{3}{*}{ Aminoglycosides } & Gentamycin & 3 & 0.68 \\
\hline & Tobramycin+Polymyxin B+Hydrocortisone & 6 & 1.37 \\
\hline & Total & 9 & 2.05 \\
\hline \multirow[t]{3}{*}{ Macrolides } & Azithromycin & 40 & 9.15 \\
\hline & Clarithromycin & 13 & 2.97 \\
\hline & Total & 53 & 12.12 \\
\hline Grand total & & 437 & $100 \%$ \\
\hline
\end{tabular}


Table 5: Most commonly used agent of a particular class

\begin{tabular}{|c|c|c|c|}
\hline Category & Most commonly used agents & No. of agent prescribed & $\%$ consumption \\
\hline \multicolumn{4}{|l|}{ Beta-lactams } \\
\hline Penicillins & Amoxicillin with clavulanic acid & 91 & 20.82 \\
\hline Cephalosporins & Cefuroxime & 23 & 5.26 \\
\hline Quinolones & Gemifloxacin & 61 & 13.95 \\
\hline Chloramphenicol & Chloramphenicol & 44 & 10.06 \\
\hline Macrolides & Azithromycin & 40 & 9.15 \\
\hline Sulphonamide & Co-trimoxazole & 17 & 3.89 \\
\hline Aminoglycosides & Neomycin with polymyxin B & 6 & 1.37 \\
\hline
\end{tabular}

Table 6: Type of antibiotics therapy

\begin{tabular}{lll}
\hline Drugs prescribed & No. of prescription & \% \\
\hline Single antibacterial agent (One drug) & 60 & $54.54 \%$ \\
Two drugs & 14 & $12.72 \%$ \\
Three drugs & 8 & $7.27 \%$ \\
Four drugs & 10 & $9.09 \%$ \\
More than four antibiotic agents & 18 & $16.36 \%$ \\
Total & 110 & $100 \%$ \\
\hline
\end{tabular}

Average number of antibacterial prescribed per patient per course

The average number of antibiotic agents prescribed per patient per course was found to be 3.97 table 7 .

\section{Routes of administration}

A total of 437 antibiotics were prescribed to110 patients. Their routes of administration were oral (298), parenteral (i. v) (81) and Topical (inhalation) (58) fig. 4.

Table 7: Number of antibiotics agents prescribed per patient per course

\begin{tabular}{ll}
\hline Total number of antibiotic agents & 437 \\
Total number of patients & 110 \\
Avg. no. of antibiotics agents prescribed per patient per course & 3.97
\end{tabular}

Avg. no. of antibiotics agents prescribed per patient per course

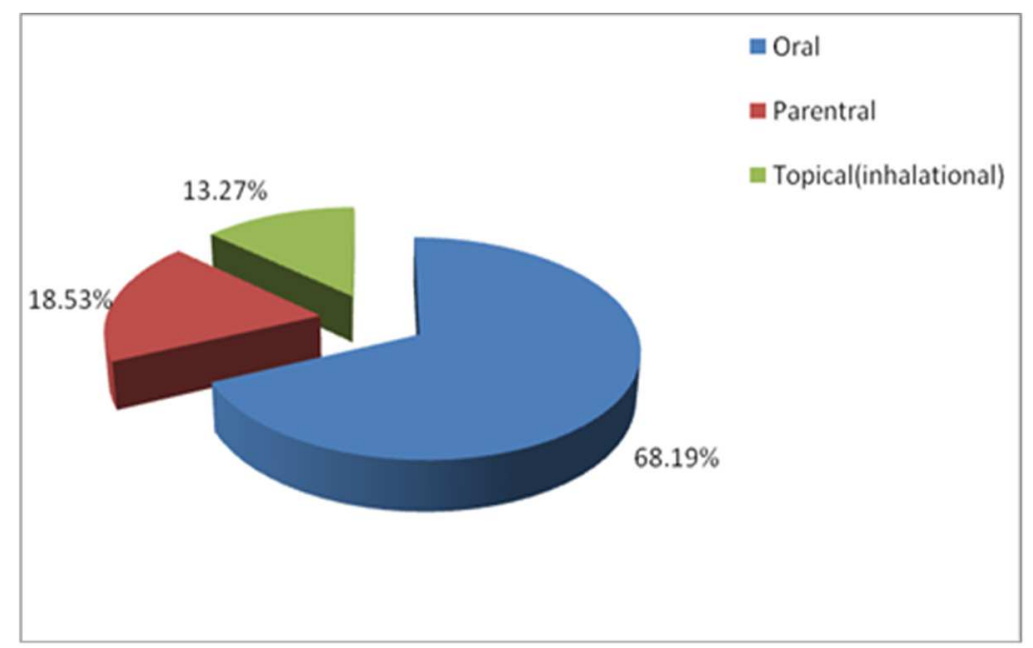

Fig. 4: Route of administration

\section{Concomitant conditions}

The most frequent concomitant conditions of the study population were found to be diabetes (25.45\%) followed by hypertension (16.36\%), coronary artery disease $(11.81 \%)$ and others are mentioned in table 8.

\section{Comparison of prescribed antibiotics as generic vs. brand names}

All the antibiotics agents were prescribed by their brand names only.

\section{Patient's adherence}

Weekly diary cards were used for daily drug intake to monitor adherence to the prescribed dosage regimen. Criteria for non- compliance were $<80 \%$ of recommended intake of prescribed drugs table 9.

Adverse drug reaction monitoring of antibiotics use inLRTI patients

Adverse drug reaction monitoring was also carried out simultaneously in LRTI patients.

\section{ADRs among various age groups in LRTI patients}

The prevalence of ADRs was found to be highest in patients between $56-65$ y (26.08\%) followed by $46-55$ y (17.39\%) fig. 5. 
Table 8: Concomitant conditions

\begin{tabular}{lll}
\hline Concomitant conditions & No. of patients & \% of patients \\
\hline Diabetes & 28 & $25.45 \%$ \\
Hypertension & 18 & $16.36 \%$ \\
Coronary artery disease & 13 & $11.81 \%$ \\
Hypothyroidism & 9 & $8.18 \%$ \\
Rheumatoid arthritis & 7 & $6.36 \%$ \\
Depression & 6 & $5.45 \%$ \\
Tuberculosis & 2 & $1.81 \%$ \\
Epilepsy & 2 & $1.81 \%$ \\
CHF & 1 & $0.90 \%$ \\
Hyperthyroidism & 1 & $0.90 \%$ \\
Hypertension+Diabetes & 2 & $1.81 \%$ \\
Hypertension+R. arthritis & 1 & $0.90 \%$ \\
Diabetes+R. arthritis & 1 & $0.90 \%$ \\
Total & 89 & $82.64 \%$ \\
\hline
\end{tabular}

Table 9: Patients adherence

\begin{tabular}{llll}
\hline Patients adherence & Male & Female & \% of patients \\
\hline$<80 \%$ (Poor compliance) & 50 & 10 & $54.54 \%$ \\
$\geq 80 \%$ (Good compliance) & 20 & 30 & $45.45 \%$ \\
\hline
\end{tabular}

50 of total patients showed a good adherence with the prescribed treatment. Adherence was found to be slightly better in females than in the male.

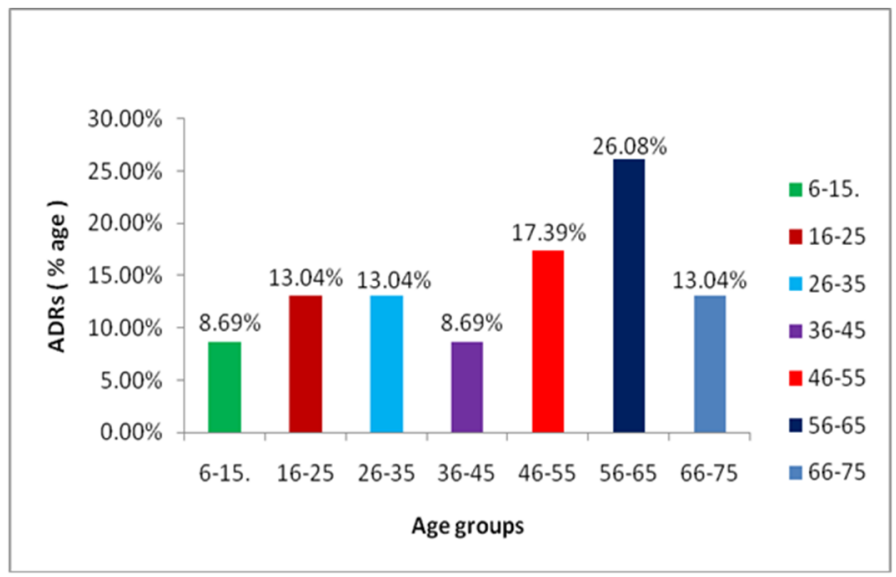

Fig. 5: ADRs among various age groups in LRTI patients using antibiotics

Table 10: ADRs and therapeutic medication

\begin{tabular}{|c|c|c|c|c|}
\hline Class & Drugs & Adverse reaction & No. of ADRs & Intervention \\
\hline \multirow[t]{11}{*}{ Beta-lactams } & Amoxicillin+Clavulanic acid & Loss of appetite & 3 & Symptomatic treatment was given \\
\hline & & Loss of appetite & & Symptomatic treatment was given \\
\hline & & Loss of appetite & & Symptomatic treatment was given \\
\hline & & Nausea/vomiting & 2 & Symptomatic treatment was given (antiemetic) \\
\hline & & Nausea/vomiting & & Symptomatic treatment was given (antiemetic) \\
\hline & & Breathing problem & 1 & Dechallenge \\
\hline & Amoxicillin & Epigastric distress & 1 & Symptomatic treatment was given (anta acid) \\
\hline & & Nausea/vomiting & 1 & Symptomatic treatment was given (antiemetic) \\
\hline & & Diarrhoea & 1 & Dechallenge \\
\hline & Cefixime & Urticaria & 1 & Dechallenge, Symptomatic treatment was given \\
\hline & Cefaclor & Skin rash & 1 & Dechallenge \\
\hline \multirow[t]{8}{*}{ Quinolones } & Norfloxacin & Abdominal pain & 1 & Symptomatic treatment was given \\
\hline & & Dizziness & 1 & Dechallenge \\
\hline & Levofloxacin & Headache & 1 & Symptomatic treatment was given \\
\hline & Ofloxacin & Vomiting & 1 & Symptomatic treatment was given (antiemetic) \\
\hline & Gemifloxacin & Diarrhoea & 2 & Dechallenge \\
\hline & & Diarrhoea & & \\
\hline & & Loss of appetite & 2 & Symptomatic treatment was given \\
\hline & & Loss of appetite & & Symptomatic treatment was given \\
\hline \multirow[t]{3}{*}{ Macrolides } & Clarithromycin & Altered taste & 1 & None \\
\hline & Azithromycin & Chest pain & 1 & Dechallenged \\
\hline & & Rash & 1 & Dechallenged \\
\hline Sulphonamide & Co-timoxazole & Folate deficiency & 1 & Symptomatic treatment was given \\
\hline
\end{tabular}


Table 11: Classification of ADRs according to Naranjo's scale

\begin{tabular}{lll}
\hline Assessment score & No. of ADRs & \% of ADRs \\
\hline UNLIKELY; $\leq 0$ & 0 & $0 \%$ \\
POSSIBLE; $1-4$ & 15 & $65.21 \%$ \\
PROBABLE; 5-8 & 8 & $34.78 \%$ \\
HIGHLY PROBABLE; $\geq 9$ & 0 & $0 \%$ \\
Total & 23 & $100 \%$ \\
\hline
\end{tabular}

\section{Gender distribution of ADRs}

A total of 23 ADRs were reported in LRTI patients. Among them $14(60.86 \%)$ were male and $9(39.13 \%)$ female. The percentage of patients experiencing ADRs was calculated from a pool of 110 antibiotics prescribed cases.

\section{ADRs and therapeutic medication}

The details of ADRs associated with the individual antibiotics agent and their therapeutic classes observed in the study (table 10).

\section{Classification of ADRs on the basis of severity}

Majority of the ADRs (69.56\%) observed were mild, which were well tolerated by the patients for e. g. nausea, GI distress, headache etc. $30.43 \%$ of ADRs were classified as moderate e. g. diarrhoea with amoxicillin-clavulanic acid. The offending drug was withdrawn and specific/symptomatic treatment was given which reversed the symptoms as the shown table below.

\section{Classification of ADRs according to Naranjo's scale}

Out of 23 ADRs, 15 (65\%) were classified as possible and 8 (35\%) ADRs were classified as probable as per Naranjo's probability scale as shown table below table 11 .

\section{DISCUSSION}

Prescription by a doctor may be taken as a reflection of physician's attitude to the disease and role of the drug in treatment. It also provides an insight into the nature of the health care delivery system. The present prospective study indicated general trends of prescribing in the outpatient and inpatient department of Medicine, Majeedia Hospital, New Delhi-110062.

During the study period of 4 mo, a total of 2100 patients (suffering from various diseases) visited the outpatient and inpatient department of Medicine, Majeedia Hospital. Out of these patients, only 110 patients met the inclusion criteria and were included in the study. Out of the total 110 patients, $74(67.27 \%)$ were males and 36 $(32.72 \%)$ females as shown in the table 1 . These observations are similar to other studies reported by $[12,13,14]$ where the presence of males was found significantly more than females in various respiratory tract infection studies. In this study also, a higher percentage of males suffering from LRTIs. However, another study [15] has shown females more sensitive to LRTI infections than males being more exposed to kitchen smoke.

In the present study, the age of the patients ranged from 6-85 y. Maximum number of patients $27.27 \%$ (30) was in the age group of $56-65$ y followed by the age group 66-75 y (19\%). Our study indicates that LRTIs are more prevalent in older patients. Few studies have reported that majority of patient's fall in different age groups like 45-60 y and greater than $60 \mathrm{y}$ with URTI [16]. Our results showed that LRTIs are predominant in older patients (age range 56-75 y).

It was also observed that a total of $27.27 \%$ of patients were current smokers, $54.54 \%$ were ex-smoker and that male's presence was predominant in both the group. $45.45 \%$ of males and $14.54 \%$ of females were found alcoholic in our study. Alcoholism and tobacco chewing are major problems of developing countries, especially in the interiors of India. Since the majority of patients visiting Majeedia hospital were from backward areas like Sangam vihar, Tughlakabad extension etc, $61.8 \%$ of tobacco chewers including $54.54 \%$ of males were observed. The study included $78.18 \%$ of outpatients and only $21.81 \%$ of inpatients at Majeedia Hospital. Out of these 110 patients,
$72(65.45 \%)$ patients were found to be suffering from bronchitis (acute-39, chronic-33) and 38 patients were found suffering from pneumonia (community acquired-23, hospital-acquired-15). Bronchitis and pneumonia along with acute exacerbations are among the most common infections worldwide and a significant cause of morbidity and mortality [17]. The prevailing bacterial pathogens implicated in community-acquired LRTIs are $S$. pneumonia that is the most common causative agent of communityacquired pneumonia (CAP).

Most commonly prescribed categories of antibiotics were found to be $\beta$-lactam (44.83\%) (Penicillin-23.1\%, Cephalosporin-21.73\%), followed by quinolones (26.27\%) and macrolides (12.12\%). The chloramphenicol and sulfonamides constituted only $10.06 \%$ and $3.89 \%$ respectively. Among the individual antibiotics drugs, maximum patients had taken a combination of amoxicillin with clavulanic acid (20.82\%), followed by gemifloxacin (13.95\%), chloramphenicol (10.06\%), azithromycin (9.15\%), ofloxacin $(6.17 \%)$ and cefuroxime (5.26\%). In our study observed only $12.12 \%$ of cases were prescribed such broad-spectrum antibiotics. A change in the prescribing patterns from a small spectrum to penicillin to amoxicillin-clavulanate, as indicative in our study. It could be due to an increase in antibiotic resistance which encourages physicians to choose a broader and safer option. We observed that $54.54 \%$ patients taken antibiotic monotherapy and the remaining patients were on multiple therapy receiving 2,3 or 4 drugs per prescription. The average number of antibiotic agent prescribed per patient per course was found to be 3.97. An average of 3.75 drugs per prescription indicates polypharmacy. Since it increases the risk of adverse effect, drug interaction increases cost and reduce patient compliance; it is an area of concern requiring intervention.

The routes of administration of antibiotics were found to be oral (81.81\%), parenteral (9.09\%) and topical (inhalation) (9.09\%). It has been observed that the trend of prescribing drugs under the generic name is declining [15]. We found that none of the drugs was prescribed by generic names. Such practice may be an evidence of vigorous promotional strategies by pharmaceutical companies. It may undermine some of the goals of essential drug concept. On the other hand, prescribing by generic name may reduce overall expenditure on drugs especially on newer antibiotics etc. The practice of prescribing drugs by brand name thus should be discouraged as the use of generic is a cheaper alternative.

A significant number of patients $(82.64 \%)$ were found to be suffering from concomitant diseases. The most frequent concomitant condition of the study population was found to be diabetes $(25.45 \%)$, followed by hypertension $(16.36 \%)$, coronary artery disease $(11.81 \%)$, hypothyroidism $(8.81 \%)$ and rheumatoid arthritis (3.63\%). Further, only $50(45.45 \%)$ patients had taken the drug properly. For studying patients compliance weekly diary cards where used. Cost of antibiotic could be one of the important factors for noncompliance in developing countries like India. Inadequate information about the disease, adverse effect of the drugs, use instructions and cautions are the other reasons of patients noncompliance [18].

We evaluated the safety of the treatment by monitoring the ADRs throughout the study period. Only $20.91 \%$ of patients had complaints of ADRs. The prevalence of ADR was found to be highest in patients between 56-65 y followed by 46-55 y (17.39\%). Most of the ADRs were mild (69.56\%) such as nausea, vomiting, loss of appetite etc. $(30.43 \%)$ were moderate such as diarrhea. Maximum ADRs were reported with the combination of amoxicillin and 
clavulanic acid $30.40 \%$ followed by gemifloxacin (17.4\%). Diarrhea is a common side effect of antibiotic therapy. In the present study, either the antibiotic therapy was de challanged or symptomatic treatment was a given for most of the ADRs reported which reversed the symptoms. ADRs were assessed using Naranjo's probability scale which showed that 15 ADRs (65.21\%) were a possible reaction and $8(34.78 \%)$ were a probable reaction. This study showed that most of the ADRs were mild (69.56\%). None of the ADRs was severe or life-threatening.

\section{CONCLUSION}

It concluded that it is preferable to keep the lesser utilization of antibiotics in LRTI infection since some of the LRTIs are not due to bacteria. Prescribing drug by generic name and not by brand name could lead to cheaper treatments. It appears that majority of the LRTIs coming to the hospital are primarily due to bacteria, most of the patients responded well with the use of antibiotics. Majority of the patients used drug regimen to the current treatment guidelines. The study highlighted some rational prescription patterns including the lesser rate of injection in OPD. The area of concern is polypharmacy, high rate of antibiotic prescribing etc. Initiative must be taken to minimize polypharmacy concerning to the antibiotics prescribing for LRTI infections.

\section{AUTHORS CONTRIBUTIONS}

Data collection process was performed by Md. Shamim, while Md. Sarafaraz Alam and Salahuddin conducting a review on questionnaire and data analysis. Mohammad Daud Ali contributed on the design of the questionnaire, supervising data analysis process and writing manuscript. Arrangement of the manuscript as per journal demand did by Dr. Md. Sajid Ali. Manuscript reviewed throughout for their rectifying grammar error done by Dr. Md. Sarfaraz Ahmed.

\section{CONFLICT OF INTERESTS}

There are no conflicts of interest

\section{REFERENCES}

1. Nagapuri S. Market research on the usage of antibiotics in serious infections. Int J Pharm Pharm Sci 2014;6:371-4.

2. Shyama K, Rudence AR. Improving antibiotic prescribing pattern and assessment of co-morbidities associated with respiratory tract infections. Int J Pharm Pharm Sci 2017;9:283-6.

3. Morrissey I, Maher K Williams, L Shackcloth J, Felmingham D Reynolds R. Non-susceptibility trends among Haemophilus influenzae and Moraxella catarrhalis from community-acquired respiratory tract infections in the UK and Ireland, 1999-2007. J Antimicrob Chemother 2008;62 Suppl 2:ii97-ii103.
4. Belongia EA, Naimi TS, Gale CM, Besser RE. Antibiotic use and upper respiratory infections: a survey of knowledge, attitudes, and experience in wisconsin and minn-esota. Preventive Med 2002;34:346-52.

5. Graffelman AW, Neven AK, Cessie SL, Kroes ACM, Springer MP, Broek PJVD. Pathogens involved in lower respiratory tract infections in general practice. Br J Gen Pract 2004;54:15-9.

6. North Melbourne: Therapeutic Guidelines Limited; 2000.

7. Jakobsen KA, Melbye H, Kelly MJ, Ceynowa C, Molst S, Hood K Butler C. Influence of CRP testing and clinical findings on antibiotic prescribing in adults presenting with an acute cough in primary care. Scand J Primary Health Care 2010;28:229-36.

8. Currie J, Thomas D, Eliana G. Early Childhood Economic Program; 2001;15:2:213-238.

9. Nordenberg P, Dominique LM, Otto C. Priority medicine for europe and the world: a public health approach to innovation. Available from: http://mednet3.Who.int/proritymeds/2005. [Last accessed on 20 Nov 2017]

10. Huchon GJ, Gialdroni-Grassi G, Leophonte P, Mansare F, Schaberg T, Woodhead M. Initial antibiotic therapy for lower respiratory tract infection in the community: a European survey. Eur Respire J 1996;9:1590-5.

11. Guthrie R. Community-acquired lower respiratory tract infections: etiology and treatment. Ther Guidelines: Respiratory 2009;6:503-89.

12. Pradhan SC, Shewade DG, Tekur U, Zutshi S, Pachiappan D, Dey $\mathrm{AK}$, et al. Changing pattern of antimicrobial utilization in an Indian teaching hospital. Int J Clin Pharmacol Ther Toxicol 1990;28:339-43.

13. Mathew E, Falagasa B, Eleni GM, Konstantions ZV. Sex differences in the incidence and severity of respiratory tract infections. Respir Med 2007;101:1845-63.

14. Shankar PR, Upadhyay DK, Subish P, Dubey AK, Mishra P. Prescribing patterns among paediatric inpatients in a teaching hospital in Western Nepal. Singapore Med J 2006;47:261-5.

15. Dhingra PL. Diseases of ear, nose and throat. $3^{\text {rd }}$ ed. New Delhi: Mosby, Saunders, Elsevier; 2004. p. 62-117.

16. Mazzaglia G, Greco S, Lando C, Cucinotta G, Caputi AP. Adult acute upper respiratory tract infections in sicily: pattern of antibiotic drug prescription in primary care. J Antimicrob Chemother 1998;41:259-66.

17. Pandey A, Chaudhry R, Kapoor L, Kabra S. Acute lower respiratory tract infection due to chlamydia species in children under five years of age. Indian J Chest Dis Allied Sci 2005;47:97-101.

18. Ryan HS. Pattern of drug utilization in acute tonsillitis in a teaching hospital in Nepal. Indian J Otolaryngol Head Neck Surg 2003;3:176-9. 